\title{
PALAVRAS E IMAGENS EM UM UNIVERSO DUPLICADO: UMA REPRESENTAÇÃO IMAGÉTICA DE 1Q84, DE HARUKI MURAKAMI
}

\author{
WORDS AND IMAGES IN A DUPLICATED UNIVERSE: AN IMAGECTIC \\ REPRESENTATION OF 1Q84, BY HARUKI MURAKAMI
}

Cacio José Ferreira ${ }^{1}$

Norival Bottos Júnior ${ }^{2}$

Akashi Hashimoto ${ }^{3}$ Rebecca Abensur Bastos ${ }^{4}$

Recebido em: 23 dez. 2018

Aceito em: 19 mar. 2019

DOI 10.26512/aguaviva.v4i2.23215

RESUMO: Este artigo analisa algumas possibilidades de interpretação da obra 1Q84, de Haruki Murakami, utilizando-se o procedimento de investigação e descrições imagéticas como experiências literárias, discutindo, a partir dos três tomos que compõem a obra, as relações entre linguagem escrita e imagens produzidas pelo leitor. Trabalha-se, sobretudo, a noção de cartografia de imagens, a intertextualidade que a produção de imagens proporciona ao descrever o devir-imagem na literatura. Como aporte teórico, utiliza-se as reflexões de autores como Maurice Blanchot, Georges Didi-Huberman, Michel Foucault e Roland Barthes, entre outros.

Palavras-chave: Imagem; efeito estético; espaços - outros; ilustração de personagens.

\begin{abstract}
The article analyzes some possibilities of interpretation of the work 1Q84, by Haruki Murakami, using the procedure of investigation and description of images as literary experiences. The discussion is based on three volumes that make up the work as relations between written language and images that are produced by the reader. The article works in particular with the notions of cartography of images, the intertextuality that produces new possibilities among the text and the images that are able to describe the time-images in literature. As theoretical support, are used the reflections of thinkers like Maurice Blanchot, Georges Didi-Huberman, Michel Foucault and Roland Barthes, among the others.
\end{abstract}

Keywords: Images; Aesthetic effects; Other-spaces; Illustration of characters.

\footnotetext{
${ }^{1}$ Professor de literatura japonesa da Universidade Federal do Amazonas (UFAM). E-mail: caciosan@ hotmail.com

${ }^{2}$ Doutor em Estudos Literários pela Universidade Federal de Goiás (UFG). E-mail: nonobottos@ @mail.com

3 Estudante de Letras - Língua e Literatura Japonesa da Universidade Federal do Amazonas (UFAM). E-mail: ornella.akemi@gmail.com

${ }^{4}$ Estudante de Letras - Língua e Literatura Japonesa da Universidade Federal do Amazonas (UFAM). E-mail: rebeccaabensur@gmail.com
} 


\section{INTRODUÇÃO}

Brandindo sua imaginação como um honorável samurai brandiria sua espada nos tempos antigos, Haruki Murakami dota 1Q84 (2009/2010 $)^{5}$ de uma narrativa que nasce de uma linguagem que destitui, de imediato, o poder de afirmar uma autoridade ou mesmo, um foi assim $^{6}$ imperscrutável, porque a literatura pode ser, sobretudo, linguagem figurativa e desejo de negação:

[...] O limite não está fora da linguagem, ele é o seu fora: é feito de visões e audições não linguageiras, mas que só a linguagem torna possíveis. Por isso há uma pintura e uma música próprias da escrita, como efeitos de cores e de sonoridades que se elevam acima das palavras. É através das palavras, entre as palavras, que se vê e se ouve. [...] (DELEUZE, 2011, p. 09).

O fora da linguagem não significa outra coisa senão uma cisão que sempre ouve entre a linguagem escrita literária e a imagem que ela suscita. Talvez apenas a eterna separação entre linguagem e imagem possa traçar perfis e contornos de personagens dotadas de vida interior, concedendo uma identidade na linguagem e dotando, no estilo dos seus traços, uma imagem possível de uma visão muito particular da vida e do mundo que essas personagens compartilham com os leitores, porém, trata-se de uma relação sempre inacabada e pronta a diluir-se em si mesma, como, aliás, caberia a uma pura linguagem, caso ela existisse.

Para além da palavra escrita, que se direciona para a estranha fruição sem destino, resta à imagem que a palavra evoca nos desvãos de sua adesão à obra uma incerteza, uma indecisão, um intervalo de prazer, ou, dito de outro modo, uma imagem-sobrevivente: “[...] Quais são as chances de aparição ou as zonas de apagamento, as potências ou as fragilidades? A que parte da realidade - o contrário de um todo - a imagem pode hoje se dirigir?" (DIDI-HUBERMAN, 2011, p. 43).

Imagem como traço estético, erotismo da imagem que se cria no prazer da leitura, nos dizeres de Roland Barthes: "[...] A língua se reconstrói alhures pelo fluxo apressado de todos os prazeres da linguagem” (BARTHES, 1987, p. 13). Ou seja, ao mesmo tempo prazer puro, único, mas também procedimento capaz de fazer com que a linguagem desapareça e em seu lugar faça emergir outra

\footnotetext{
${ }^{5} \mathrm{O}$ romance $1 Q 84$ foi publicado no Japão em 2009 e 2010. Esse artigo utiliza a tradução brasileira realizada por Lica Hashimoto em 2012 e 2013, publicado pela Editora Objetiva.

${ }^{6}$ Grifo nosso.
} 
possibilidade para a vida, para os dilemas da vida em sua relação contínua e inacabada com a arte. Podese afirmar que há algo de inelutável e ambíguo que atrai a análise literária para o campo da produção de outras formas de linguagem, como as imagens que sempre gravitam em torno de sentidos possíveis. A relação entre a literatura e a imagem se constitui numa evocação paroxística, pois ambas nunca param de aludirem-se umas às outras, a cisão produzida entre elas é vazão, pois, o que emerge é sempre imagem de uma linguagem que habita o espaço da escrita e, além disso, não se deve jamais esquecer os restos de imagens que se perderam nos desvãos da memória no processo de escritura, são as sobrevivências dessa relação conflituosa e que não diz respeito a um autor e um leitor, mas, antes, à infindável superação da instância entre ambas instâncias pelo prazer do texto como fruição estética e política na relação com os dilemas da vida. Nesse sentido, Foucault (2001) postula:

[...] um nome de autor não é simplesmente um elemento em discurso [...] assegura uma função classificatória; tal nome permite reagrupar um certo número de textos, delimitálos, deles excluir alguns, opô-los a outros. [...] o nome do autor funciona para caracterizar um certo modo de ele ser do discurso: para um discurso, o fato de haver um nome de autor, o fato de que se possa dizer "tal pessoa é o autor disso". Indica que esse discurso não é uma palavra cotidiana, indiferente, uma palavra que se afasta, que flutua e passa, uma palavra imediatamente consumível, mas que se trata de uma palavra que deve ser recebida de uma certa maneira e que deve, em uma dada cultura, receber um certo status. Chegar-se-ia finalmente a ideia de que o nome de autor não passa, como o nome próprio, do interior de um discurso ao indivíduo real e exterior que o produziu, do interior de um discurso ao indivíduo real e limites dos textos, que ele os recorta, segue suas arestas, manifesta o modo de ser ou, pelo menos, que ele o caracteriza. Ele manifesta a ocorrência de um certo conjunto de discurso, e refere-se ao status do autor não está localizado no estado civil dos homens, não está localizado na ficção da obra, mas na ruptura que instaura um certo grupo de discursos e seu modo singular de ser (FOUCAULT, 2001, p. 271).

A referência à ruptura pode ser a pista de um reconhecimento das vozes nos textos e assim, não havendo a marca de uma autoria dominadora do texto, o que surge é a mediação, a forma dialógica da obra de arte. $\mathrm{O}$ escritor preocupado com a mediação e a escrita contesta e rompe normas, por seu turno, o tempo e o espaço, elemento de peculiar importância no solo literário que converge para uma melhor reflexão sobre os personagens, pois o espaço e o tempo o afetam, pois suas reações dependem dos lugares em que estão inseridos, dependem do contexto histórico que os perpassa, entre espaço, tempo e personagens só pode haver uma harmonia, o efeito estético: ação, personagens, e o ir e vir que se estabelece nessas relações são cruciais.

O caráter de determinado personagem é produzido em grande medida pelos efeitos que certos espaços e situações produzem na sua afecção, no modo como interagem em algum setor da sociedade. 
Mas qual seria o significado desse tempo-espaço para um escritor e sua obra? O tempo é o cerne da narrativa. Ele nutre toda a vida da criação e está inseparavelmente ligado a ela. Nesse raciocínio, Osman Lins afirma que:

[...] o espaço move constantemente o escritor a necessidade de romper normas, de contestar o que aparece assentado. Não seria, por exemplo, a destituída de interesse uma narrativa na qual o espaço se construísse a partir da personagem. Tal narrativa, aliás, já tem seu modelo no Gênesis e em outros mitos cosmogônicos (LINS, 1976, p. 72).

A partir desse raciocínio, pode-se perceber que não há nenhum detalhe numa obra literária que não mereça atenção, mesmo os exemplos mais singelos, como, por exemplo, uma gota d'água caindo, o voo de um pássaro iluminado, o vento mexendo com as folhas de uma árvore revelam pedaços de tempos e espaços, mas o leitor, com a percepção aguçada, deve dispor da capacidade de decifrar, entender que o tempo e o espaço podem surgir até mesmo dos gestos de um personagem.

$\mathrm{O}$ ato da escrita supõe escolhas - dos detalhes mais aparentemente insignificantes àqueles que assumem papel decisivo na trama - e, por cada uma delas, os relâmpagos imaginativos do escritor delineiam e engendram a invenção, possibilitando a armação de um mundo que ainda assim não está pronto, que está à espera do leitor, à espera de imagens.

A evocação da imagem é a necessária inquietação de concluir em escalas imaginativas onde, quando e por que aquele mundo se desvela de tal forma. O universo ali ordenado condensa uma espécie de completude. Nesse viés, Osman Lins afirma que: "O homem diante de uma página em branco é o homem mais livre do mundo" (LINS, 2005, p. 245).

A palavra cultivada na página transforma-se em literária e não aceita a imposição de uma única verdade, mas conduz o escritor ao enquadramento do mundo sob múltiplas performances. Maurice Blanchot (1987) amplia essas possibilidades ao afirmar que aquele que escreve

parece senhor de sua caneta, pode tornar-se capaz de um grande domínio consegue apenas colocá-lo e mantê-lo em contato com a profunda passividade em que a palavra, não sendo mais do que sua aparência e a sombra de uma palavra, nunca pode dominada nem mesmo apreendida, mantém-se inapreensível, o momento indeciso da fascinação (BLANCHOT, 1987, p. 15). 
Portanto, a página em branco preenchida pela palavra pode revelar contornos que rememoram um quadro pendurado em uma parede. Sendo assim, é possível mediar a história, principalmente os personagens, por meio da identidade criada pelo autor e configurar as imagens deles. Assim, o presente artigo tem como objetivo criar certos contornos ilustrativos das personagens de 1Q84 seguindo de perto as descrições identitárias conferida pelo autor.

\section{O tempo, o não-lugar e os espaços-outros na criação imagético em $1 Q 84$}

A intenção dessa investigação é evidenciar o fato de que é possível alargar o horizonte de interpretação do texto narrativo pela via da criação de desenhos por parte do leitor que é o responsável pela fruição da obra, trata-se, assim, de uma visão por meio do desenho, que um estudo comparativo da ótica da caracterização do personagem, tempo e espaço pode proporcionar, principalmente por se tratar de uma investigação de natureza intertextual - e não pautada por influências, mas por confluências: autores, palavras, obras, desenhos, mundos, invenções/criações, produção ininterrupta de devires múltiplos e informes, capazes de aproximar a leitura como devir da produção artística, livrando-a da pura mimese, como afirma Gilles Deleuze:

[...] A literatura está ao lado do informe, ou do inacabamento [...]. Escrever é um caso de devir, sempre inacabado, sempre em via de fazer-se, e que extravasa qualquer matéria visível ou vivida. [...] Devir não é atingir uma forma (identificação), imitação, Mímese, mas encontrar a zona de vizinhança, de indiscernibilidade ou indiferenciação tal que já não seja possível distinguir-se de uma mulher, de um animal ou de uma molécula (DELEUZE, 2011, p. 11).

No processo de produção de ilustrações, de imagens pictóricas de uma obra narrativa, personagem, tempo e o espaço são os elementos mais importantes para fluidez e a densidade dessa confluência. Nesse sentindo "os mistérios do mundo passam a caber na palma da mão, como uma ostra" (MURAKAMI, 2012, p. 389). Os três livros que formam 1Q84, assim como a utilização do site oficial do autor e diversos outros artigos para se ter um entendimento mais amplo e diverso sobre a obra em questão, formaram também esse emaranhado de confluências na busca pela criação de imagens que se relacionassem com a obra, buscando assim, adicionar camadas, onde: 
Este mundo fictício ou mimético, que frequentemente reflete momentos selecionados e transfigurados da realidade empírica exterior à obra, torna-se, portanto, representativo para algo além dele, principalmente além da realidade empírica, mas imanente à obra (ROSENFELD, 2002, p. 15).

O romance 1Q84 descreve a vida cotidiana da sociedade japonesa com algumas notáveis diferenças: realidades paralelas, amores perdidos, assassinatos, seitas extremistas e pequenas criaturas determinadas a não serem esquecidas. É nesse mundo onde "as coisas não são o que aparentam ser"7 , que os personagens são recriados em desenho a partir de descrições, veja-se por exemplo: Aomame, uma mulher determinada, cujo segundo trabalho (ser assassina) necessita de um foco implacável e preciso. Tengo, um professor de matemática cuja receosa paixão é a escrita. Komatsu, um oportunista visionário. Fukaeri, uma misteriosa estudante colegial autora de um livro que pode mudar o mundo.

Todos os personagens mencionados passam por momentos de turbulências em suas vidas, encontrando-se e desencontrando-se por meio do tempo-espaço, ligados inevitavelmente por uma sucessão de eventos. O foco deste artigo, no entanto, não são as vidas desses personagens, mas sim como eles atravessam a perspectiva da imaginação, como se apresentam na forma de um devir-imagem, de que maneira se tornam uma realidade possível por meio de suas descrições passadas, desenhadas, postas no papel em formas de imagens.

Murakami busca sempre surpreender o desejo do leitor ao final da narrativa. Sua escrita, principalmente em 1Q84, é carregada de detalhes em alguns momentos, e escassos em outros. Marcas de roupas famosas como as da Fashion Designer Japonesa Junko Shimada ou os sapatos Charles Jourdan, assim como a Sinfonietta de Leoš Janáček aparecem na obra em detalhes largos. Entretanto, é importante dar ênfase ao fato de que mesmo o autor usando, em grande parte, o surrealismo, essas marcas famosas existentes na nossa realidade, findam dando um quê de questionamento e abrindo as portas para discussões sobre até que ponto a pós-modernidade pode separar a pretensa realidade da ficção. Dessa maneira, as descrições dos personagens a seguir, retiradas de 1Q84, são necessárias para a compreensão das imagens realizadas.

Aomame caminhou com os passos firmes, a postura ereta, o queixo retraído, os olhos atentos à frente, sentindo na pele uma enxurrada de olhares sobre ela. Os saltos de seu Charles Jourdan castanho pisavam firmemente no pavimento ressoando batidas secas, e o vento se incumbia de agitar as abas de seu casaco. Era abril, mas os ventos ainda gelados traziam consigo um pressentimento hostil. Ela vestia um casaco de meia-estação bege

\footnotetext{
${ }^{7}$ MURAKAMI, 2012, p. 18.
} 
sobre o conjunto de blazer e saia verde, de tecido fino de lã, da Junko Shimada, e carregava uma bolsa de alça de couro preta. Seus cabelos na altura do ombro tinham um belo corte e eram bem-cuidados. Não usava nenhum tipo de acessório ou algo parecido. Tinha um metro e sessenta e oito de altura, músculos firmes, nenhum excesso de gordura, mas essa parte do corpo o casaco não deixava revelar.

Ao observar atentamente o seu rosto, notava-se que o formato e o tamanho de sua orelha direita eram consideravelmente diferentes dos da esquerda. Além de a orelha esquerda ser bem maior que a direita, era também disforme. Normalmente ninguém notava essa diferença oculta pelos cabelos. Seus lábios, quando cerrados, desenhavam uma linha reta que lhe conferia um ar pouco expansivo. E o nariz pequeno e fino, as bochechas salientes, a testa larga, as sobrancelhas longas e retas reforçavam ainda mais esse tipo de personalidade antissocial. Seu rosto era mais para oval. Gostos à parte, ela podia ser considerada bonita. $\mathrm{O}$ único, porém, era a extrema inexpressividade de seu rosto. Seu olhar, como o de um exímio vigia de convés, era friamente indolente. $\mathrm{E}$, sendo assim seu rosto nunca causava uma boa impressão às pessoas. Nem sempre o que chama atenção e atrai as pessoas é o fato de a fisionomia ser bela ou feia, mas naturalidade e o refinamento com que a pessoa sabe se expressar.

A maioria das pessoas não conseguia gravar as feições de seu rosto. Bastava desviar os olhos dela para não serem mais capazes de descrevê-lo. Digamos que, apesar de seu rosto possuir características singulares, estas, por incrível que pareça, nunca eram memorizadas. Nesse sentido, ela era como um inseto que habilmente mimetiza o ambiente. E conseguir se camuflar, mudando de cor e formato, e, ainda não chamar a atenção e ser uma pessoa difícil de ser lembrada era, de fato, o que Aomame mais desejava. Desde pequena, era o seu jeito de se proteger.

No entanto, quando algo a desagradava, o semblante até então apático sofria uma radical transformação. Notava-se uma drástica contração dos músculos faciais a destacar exageradamente a assimetria entre o lado direito e o esquerdo de seu rosto, um rosto que se deixava frisar por rugas bem acentuadas, olhos afundados, nariz e boca embrutecidos e tortos, queixo repuxado para um dos lados e lábios arreganhados, deixando à mostra dentes grandes e brancos (MURAKAMI, 2012, Tomo I, p. 20-21).

Komatsu era alto, magro, tinha uma boca exageradamente grande, em contraste com o nariz extremamente pequeno. Seus braços e suas pernas eram compridos, e as pontas dos dedos eram manchadas de nicotina. Sua aparência lembrava os revolucionários decadentes, típicos dos romances russos do século XIX.

Dificilmente ria, mas, quando dava risada, todo o seu rosto parecia sorrir. Mas nem por isso parecia feliz. A sua risada lembrava a de um velho feiticeiro, prestes a revelar uma profecia funesta. Era asseado e se vestia bem, mas suas roupas eram todas muito parecidas, como se dissesse ao mundo que não se importava com o vestuário: blazer de tecido de lã axadrezado, camisa polo verde-clara ou camisa branca de algodão Oxford, sem gravata, calça cinza e sapato de camurça; isso era uma espécie de uniforme para ele. Dava até para imaginar a meia dúzia de blazers de três botões com pequenas variações de cor, tecido e padronagem, todos bem escovados e pendurados no closet de sua casa. E não seria de admirar se, para distingui-los, eles fossem devidamente numerados.

Os fios de cabelo eram duros como arame e começavam a ficar grisalhos no alto da cabeça. Seus cabelos emaranhados cobriam suas orelhas e era interessante notar que ele sempre os mantinha no mesmo comprimento: de quem deveria ter ido ao barbeiro na 
semana passada. Tengo não sabia como isso era possível. De vez em quando, os olhos de Komatsu brilhavam intensamente, como estrelas reluzentes no céu de inverno. E, se por algum motivo se calava, mantinha-se em silêncio como uma rocha no lado escuro da lua. A sua inexpressividade era tanta que dava a impressão de que perdera totalmente o calor corporal (MURAKAMI, 2012, Tomo I, p. 34).

Tengo era grande e robusto (do ginásio à faculdade, sempre fora o atleta principal do time de judô), e tinha olhos de um agricultor que acorda cedo. O cabelo curtinho, a pele bronzeada e as orelhas arredondadas e amassadas como couve-flor não condiziam com a imagem de um jovem entusiasta da literatura, muito menos com a de um professor de matemática (MURAKAMI, 2012, Tomo I, p. 35).

Rosto bonito, de feições clássicas, cabelos compridos de corte reto. Blusa branca. Seu corpo era miúdo e esguio. Os lábios se esforçavam para abrir um sorriso, mas os olhos pareciam resistir. Um olhar sério. Olhar de quem busca algo (MURAKAMI, 2012, Tomo I, p. 43).

Fukaeri era pequena. Seu rosto era muito mais bonito do que na foto. O que mais chamava a atenção nesse seu rosto eram os olhos. Olhos que impressionavam pela profundidade de seu olhar. Tengo sentiu desassossego ao ser observado por esse par de pupilas reluzentemente negras. Ela praticamente não piscava. Tampouco parecia respirar. Os cabelos pareciam ter sido cortados precisamente, medidos à régua, fio a fio, em corte reto, e o formato de suas sobrancelhas combinava com esse corte. Como a maioria das garotas bonitas na faixa dos dez aos vinte anos, sua expressão carecia de vitalidade. Expressão que, por sua vez, era reforçada pelo olhar, que diferia em profundidade entre sua pupila direita e a esquerda. Um olhar assimétrico que provocava uma sensação de mal-estar para quem se tornava alvo dele. Era difícil saber o que ela pensava. Nesse sentido, ela não era do tipo de garota bonita que leva jeito para ser modelo ou que vai despontar como cantora de sucesso. Mas, em compensação, tinha um poder de estimular e atrair as pessoas (MURAKAMI, 2012, Tomo I, p. 68).

Em frente à varanda havia algumas cadeiras de jardim de teca, e um homem grande, sentado numa delas, dava a impressão de estar entalado. Ele não era alto, mas logo se notava quão desenvolvidos eram os seus músculos peitorais. Tinha cerca de quarenta anos, a cabeça totalmente rapada e um bigode bem- aparado. Vestia um terno cinza de ombros largos, camisa branca e uma gravata de seda cinza-escuro. Calçava sapatos de cordovão preto impecavelmente lustrados. E tinha um piercing de prata em cada orelha. Dificilmente seria confundido com um funcionário do departamento de contabilidade da Prefeitura, e muito menos um vendedor de seguros de automóveis. À primeira vista, parecia um guarda-costas profissional e, de fato, essa era a sua profissão. De vez em quando, era também motorista. Era altamente graduado no caratê e, se a situação assim requeresse, saberia usar armas com destreza. A impetuosidade de seu ataque o transformava numa pessoa extremamente violenta. Mas normalmente era calmo, ponderado e inteligente. Ao observar fixamente seus olhos - é claro, se ele o consentisse —, seria possível notar um brilho benevolente neles.

Pessoalmente, ele gostava de mexer em vários tipos de máquinas, colecionar discos de rock progressivo dos anos sessenta e setenta, e morava em outro ponto do bairro de Azabu com um cabeleireiro jovem e bonito. Ele se chamava Tamaru (MURAKAMI, 2012, Tomo I, p. 114). 
A Proprietária era uma mulher pequena na faixa dos setenta anos. Seus cabelos eram brancos, bonitos e curtos. Vestia um camisão de brim de manga comprida, calças de algodão creme e um par de tênis sujos. Com as mãos protegidas com luvas brancas e grossas, ela regava cada vaso, um a um, com um regador de ferro grande. $\mathrm{O}$ tamanho das roupas que usava parecia ser um número maior, mas, por serem confortáveis e deixaremna à vontade, lhe caíam bem. Sempre que Aomame se encontrava com ela, não podia deixar de sentir admiração e respeito por sua elegância natural e despretensiosa (MURAKAMI, 2012, Tomo I, p. 117).

Após cerca de dez minutos, a porta se abriu de repente e um homem magro entrou apressadamente na sala. Aparentava ter uns sessenta e cinco anos. Apesar de sua estatura ser de apenas um metro e sessenta, sua postura não lhe conferia ares de pobreza. A coluna, de tão ereta, parecia escorada numa barra de ferro, e o queixo era bem retraído. As sobrancelhas eram grossas, e os óculos de aro espesso e preto pareciam ter sido feitos propositalmente para afugentar as pessoas. Seus movimentos lembravam uma sofisticada máquina compacta com peças precisamente encaixadas e ajustadas, todas em perfeito funcionamento. Tengo fez menção de levantar para cumprimentá-lo, mas, num gesto rápido, o homem sinalizou com as mãos para que permanecesse sentado. Enquanto Tengo seguia a recomendação e voltava a se sentar, o homem, como que competindo com ele, sentou-se rapidamente na poltrona a sua frente. Ficou um bom tempo olhando para o rosto de Tengo sem dizer nada. Seu olhar não era exatamente penetrante, mas seus olhos eram atentos a tudo, aos mínimos detalhes. E, como um fotógrafo ajustando o diafragma da lente de sua câmera, seus olhos ora se estreitavam, ora se abriam (MURAKAMI, 2012, Tomo I, p. 167).

O homem vestia um suéter verde-escuro sobre uma camisa branca e uma calça de lã cinzaescura. Essas roupas pareciam fazer parte de seus hábitos cotidianos por pelo menos dez anos. Mas, apesar de terem um bom caimento, mostravam alguns sinais de desgaste. Possivelmente, era uma pessoa que não se importava muito com o que vestia ou, talvez, não tivesse alguém junto dele que se preocupasse com o que fosse usar. Os cabelos ralos destacavam o alto da cabeça, ressaltando-lhe o formato oblongo. Tinha a barba feita e o queixo quadrado. A única coisa que destoava em seu rosto era a boca pequena $\mathrm{e}$ rechonchuda, como de uma criança. Em alguns pontos do rosto havia alguns fios de barba por fazer, mas podia ser apenas o reflexo da luz. Os raios de sol dessa região montanhosa que penetravam pela janela tinham uma composição diferente daquela claridade que Tengo estava acostumado a ver (MURAKAMI, 2012, Tomo I, p. 168).

- Eu me chamo Ebisuno, disse o homem. (MURAKAMI, 2012, Tomo I, p. 169). [...] Ele era um líder nato, como Moisés guiando os hebreus. Fukada era inteligente, eloquente, com um grande poder de discernimento. E era, também, muito carismático. Tinha um aspecto robusto, digamos que tinha um físico como o seu. As pessoas naturalmente o viam como o líder do grupo e aceitavam suas decisões.

O professor abriu os braços para mostrar o físico de Fukada. Fukaeri observou a distância entre os braços e, em seguida, olhou para o corpo de Tengo, mas nada disse. 
- Fukada e eu temos personalidades e aparências totalmente diferentes. Ele é um líder nato e eu sou um lobo solitário. Enquanto ele é um indivíduo político, sou totalmente apolítico. Ele é grandalhão, eu sou pequeno. Ele é bonito e marca presença, eu sou um pobre intelectual que tem uma cabeça com formato esquisito. Mas, mesmo assim, éramos bons amigos: o respeito e a confiança eram recíprocos. Não seria exagero dizer que ele foi o único amigo que realmente tive na vida (MURAKAMI, 2012, Tomo I, p. 178).

Ushikawa era baixo e aparentava cerca de 45 anos. Era troncudo, sem cintura, e a gordura começava a se agrupar ao redor do pescoço. Em relação à idade, Tengo não estava certo. Graças a essa aparência singular (ou melhor, incomum), era difícil encontrar elementos concretos para adivinhar sua idade. Poderia ser mais velho ou mais novo. Qualquer idade entre 32 e 56 anos seria plausível, sem motivos para contestação. Os dentes eram desalinhados, e a coluna arqueada num ângulo esquisito. $\mathrm{O}$ alto da cabeça era grande, estranhamente achatado e calvo, com as pontas dos cabelos recurvas. Lembrava um heliporto militar construído estrategicamente no alto de uma colina.

Tengo vira um desses num documentário sobre a guerra do Vietnã. Os poucos cabelos pretos, de fios grossos e crespos, que ainda se agarravam ao redor da calvície estavam tão compridos que, em desalinho, cobriam as orelhas. De cem pessoas, noventa e oito certamente associariam aqueles cabelos a pelos pubianos.

Quanto às outras duas, Tengo não tinha ideia do que poderiam pensar.

Aquele homem tinha o rosto e o corpo assimétricos. Assimetria que logo saltou aos olhos de Tengo. De modo geral, o lado direito e o esquerdo do corpo são ligeiramente desiguais, mas isso pode ser considerado normal. O próprio Tengo tinha o formato da pálpebra direita um pouco diferente do da esquerda; e o testículo esquerdo também ficava um pouco abaixo do direito. O nosso corpo não é um produto fabricado em massa, com medidas padronizadas. No entanto, a diferença entre o lado esquerdo e o direito daquele homem extrapolava os limites do que se consideraria aceitável. Aquele desequilíbrio, que qualquer um podia notar, provocava em seu interlocutor um incômodo estado de nervos. Um desconforto como o de ver a própria imagem refletida num espelho distorcido, o que, ainda por cima — por refletir a imagem nitidamente —, provocava uma certa irritação.

O terno cinza que ele vestia, de tão amarrotado, lembrava uma terra devastada pela passagem de uma geleira. Uma das pontas da gola da camisa branca estava virada para fora, e o nó da gravata torto como se estivesse se contorcendo, chateado por estar naquele lugar. O terno, a gravata e a camisa eram de tamanhos ligeiramente diferentes do que deveriam ser. O padrão da gravata parecia um desenho impressionista de algum estudante de belas-artes sem aptidão, inspirado num emaranhado de fios de macarrão de trigo sarraceno. Todas as peças de sua roupa pareciam ter sido compradas em liquidação para atender uma necessidade imediata.

Mas, ao observá-las durante um tempo, Tengo passou a sentir pena daquelas roupas por terem de vestir um homem como aquele. Apesar de Tengo não se importar muito com as roupas que ele próprio usava, estranhamente reparava no modo de vestir dos outros. E, dentre as pessoas que ele conhecera nos últimos dez anos, sem dúvida aquele homem seria um dos primeiros de uma seleta lista de malvestidos. Não era só o fato de se vestir mal, mas a impressão de profanar intencionalmente o conceito de - vestuário (MURAKAMI, 2012, Tomo II, p. 31-32). 
Portanto, para sintetizar o processo de criação dos personagens e espaços, utilizou-se a comparação do real e do modo como foi imaginado pelo autor. A primeira tabela foi criada com o intuito de facilitar a compreensão do que já foi argumentado como uma espécie de cartografia da interação imagem real e imagem ficcional. Esta tabela proporciona um catálogo descritivo que pode intermediar ou mesmo facilitar a compreensão do leitor, auxiliando-o no processo de transformação de texto em imagem, sem que, no entanto, tais imagens afetem a participação do leitor, que também interage na criação de imagens, completando-as ou mesmo desconstruindo-as. Já os espaços foram ordenados na ordem cronológica que aparecem no romance e seguem a tabela abaixo:

Tabela 1 - Lugares/Acontecimentos

\begin{tabular}{|c|c|}
\hline Espaço & Acontecimentos importantes \\
\hline Chikura, Chiba & O pai de Tengo está hospitalizado nessa cidade. \\
\hline Jiyuugaoka & $\begin{array}{l}\text { Local onde se encontra o apartamento de Aomame na primeira parte } \\
\text { da narrativa. }\end{array}$ \\
\hline Via Expressa n⿳3 & $\begin{array}{l}\text { Aomame segue de táxi, no primeiro capítulo do livro, e, ao descer a } \\
\text { escada da rodovia, adentra pela primeira vez em um mundo paralelo. }\end{array}$ \\
\hline Shibuya & $\begin{array}{l}\text { Local do primeiro assassinato realizado por Aomame, e mais adiante } \\
\text { no romance, o lugar onde Ayumi é assassinada. }\end{array}$ \\
\hline Hirô & Local de trabalho de Aomame - clube de esporte. \\
\hline Azabu & Localização da mansão de Shizue Ogata. \\
\hline Roppongi & Primeiro encontro de Ayume e Aomame em um bar. \\
\hline Hotel Okura & Hotel em que Aomame assassinou o Líder. \\
\hline Ilha Sakhalin & Local de nascimento de Tamaru. \\
\hline Lago Motosu & Neste local, Akebono entrou em conflito com a polícia. \\
\hline Prefeitura de Yamanashi & Sede da Sakigake. \\
\hline Urawa, Saitama & Local de nascimento de Ushikawa. \\
\hline Uchikawa, Chiba & $\begin{array}{l}\text { Local de nascimento de Tengo e Aomame. Também é a região em que } \\
\text { se localiza a escola de tempos idos, sendo o lugar do primeiro encontro } \\
\text { (quando criança). }\end{array}$ \\
\hline Koenji & Parque em que Aomame e Tengo se encontram ao final da trama. \\
\hline Kojimachi & Região em que se localiza o escritório de Ushikawa. \\
\hline Shinanomachi & Professor Ebisuno e Fuka-Eri moram nessa região. \\
\hline Yoyogi & Local de trabalho de Tengo - cursinho preparatório. \\
\hline Nakamuraya Café & $\begin{array}{l}\text { Local de encontro dos personagens Tengo, Komatsu, Ebisuno e } \\
\text { Fukaeri (diversas vezes). }\end{array}$ \\
\hline
\end{tabular}

Fonte: Murakami, 1Q84, 2012/2013. 
Após compilar os lugares mais importantes descritos no livro, houve a necessidade de analisar todo o histórico de acontecimentos de cada lugar, para, então, selecionar por ordem cronológica aqueles que realmente podiam ser comparados com lugares reais. Terminado a seleção de lugares, foram anotadas as descrições da forma e aparência, com base de trechos descritos no romance. Os lugares foram escolhidos a partir dois critérios. Primeiro, precisariam ser lugares importantes na trama, e o segundo, que tivessem detalhes descritivos para que pudessem ser desenhados, conforme tabela a seguir.

Tabela 2 - Lugares escolhidos/trechos descritivos

\begin{tabular}{|c|c|c|c|}
\hline Espaço & Tomo & Página & Trecho descritivo \\
\hline Via Expressa $N^{\circ} 3$ & I & 17 & $\begin{array}{l}\text { À direita havia uma Mitsubishi Pajero preta, coberta por uma } \\
\text { fina camada de poeira esbranquiçada [...]. No bagageiro } \\
\text { havia várias pranchas de surfe usadas e sujas. As janelas com } \\
\text { películas estavam totalmente fechadas e, de fora, não se } \\
\text { enxergavam as pessoas em seu interior. A carroceria estava } \\
\text { tão polida que daria para ver seu rosto refletido nela. } \\
\text { Na frente do táxi em que Aomame estava, havia um Suzuki } \\
\text { alto vermelho, com a traseira levemente amassada e a placa } \\
\text { de Nerima. [...] O cenário era o mesmo de dez minutos atrás. } \\
\text { Nesses dez minutos, os carros não tinham avançado sequer } \\
\text { dez metros. }\end{array}$ \\
\hline $\begin{array}{c}\text { Nakamuraya } \\
\text { Café }\end{array}$ & I & 67 & $\begin{array}{l}\text { Após suas três aulas, Tengo pegou o trem e foi para Shinjuku. } \\
\text { Comprou alguns livros na Livraria Kinoku-niya e rumou para } \\
\text { o Nakamuraya. Na entrada, ao dizer o nome de Komatsu, } \\
\text { logo o conduziram para uma mesa tranquila que ficava nos } \\
\text { fundos do estabelecimento. [...]. Ela deixou sobre a mesa o } \\
\text { copo de água e o cardápio, e se retirou. }\end{array}$ \\
\hline Azabu, Tokyo & I & $\begin{array}{c}116 \mathrm{e} \\
117\end{array}$ & $\begin{array}{l}\text { Na enorme estufa de vidro reinava uma primavera } \\
\text { absolutamente perfeita. Flores de diversas espécies estavam } \\
\text { em plena floração, todas muito lindas. Espécies que em sua } \\
\text { maioria eram bem comuns: gladíolos, anêmonas, } \\
\text { margaridas... Dispostas por todos os lados, plantadas em } \\
\text { vasos e acomodadas em prateleiras [...]. Em compensação, } \\
\text { na estufa viviam inúmeras borboletas. Nessa enorme sala de } \\
\text { vidro, a proprietária parecia ter mais interesse em criar } \\
\text { borboletas exóticas do que plantas. }\end{array}$ \\
\hline
\end{tabular}




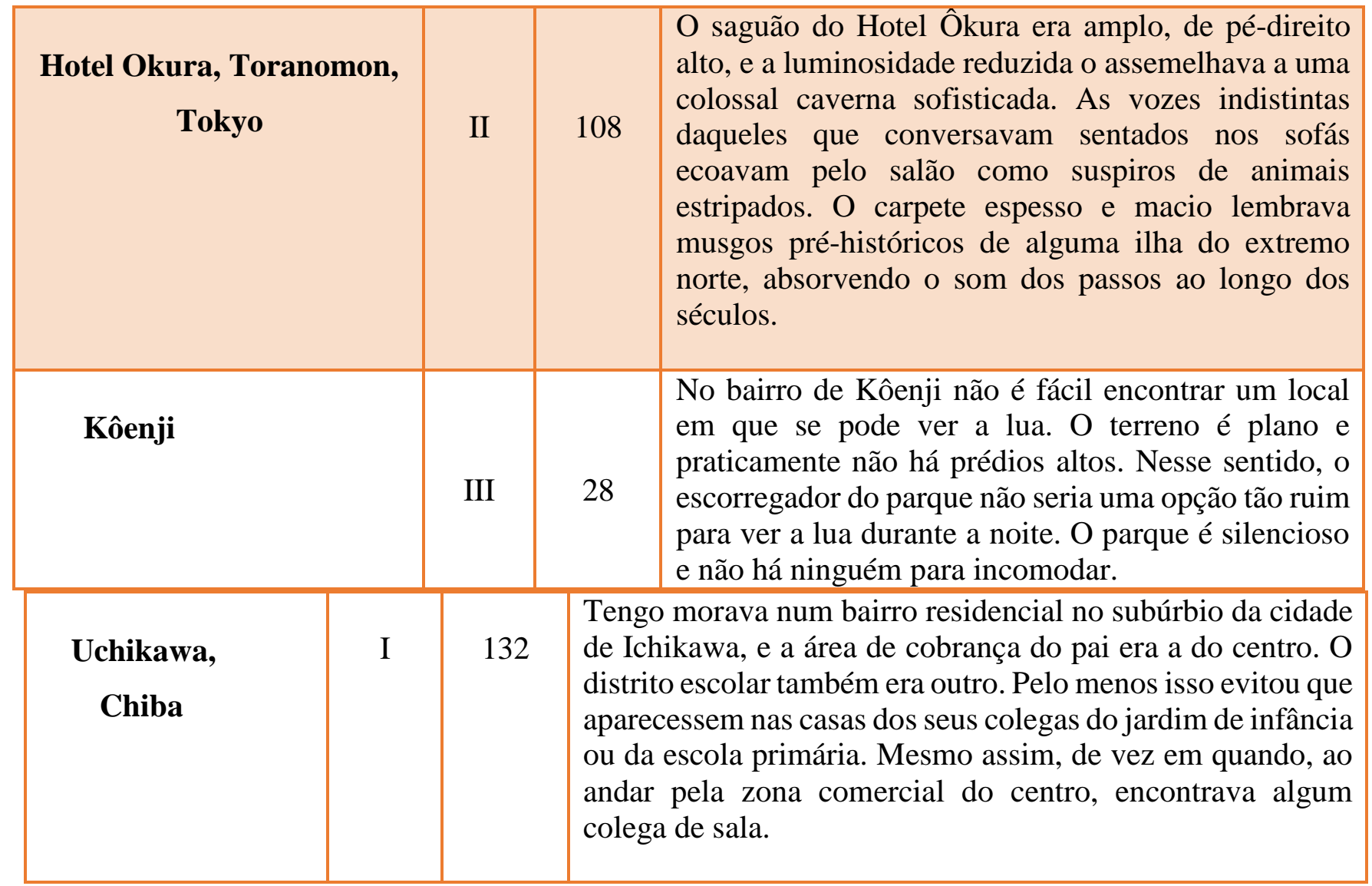

Fonte: Murakami, 1Q84, 2012/2013.

Alguns dos lugares descritos na obra tendem a ter uma falta de elementos descritivos. Nesse primeiro momento, a ilustração era necessária para que houvesse a comparação delas com fotos dos lugares reais. O trabalho levou em conta também a produção de arte conceitual $^{\mathbf{8}}$ (em anexo) estágio anterior à finalização dos desenhos.

\footnotetext{
${ }^{8}$ A Arte Conceitual é a tradução literal de Concept Art. São ilustrações que apresentam o visual de um futuro filme, game ou algo do gênero. Nesse artigo, foi utilizada para dar vida aos personagens e aos lugares descritos no romance $1 Q 84$, de Haruki Murakami. Todas as imagens presentes nesse artigo foram produzidas por Rebecca Abensur Bastos e Akashi Hashimoto.
} 


\section{CONSIDERAÇÕES FINAIS}

A leitura, a produção de ilustrações e a análise da obra $1 Q 84$ permitiram entender como se dá o processo de construção do espaço em uma narrativa. Perceber alguns recursos que o autor utiliza para desenhar o cenário com a palavra. $\mathrm{O}$ ato da criação de um texto narrativo naturalmente supõe e exige escolhas. Na rota dessa viagem, o autor acaba por engendrar a invenção e possibilitar a armação de um mundo que ainda assim não está pronto, mas que também não será completado pelo leitor, por que a obra é sempre um devir.

Nesse caminho, foi possível notar que o tempo e o espaço são resumidos nas aparências ou são completamente inseridos nas percepções e sensações para que as personagens adentrem no decorrer do texto. O universo ali ordenado simula e condensa uma espécie de completude, uma espécie de simetria do outro ou de outro lugar no mesmo caminho. É um novo inventar. Nesse sentido, com a possibilidade de poder desenhar cada cenário antes que pudesse ver as imagens reais espaços, foi possível entender alguns caminhos que o autor percorre e depois os apaga. Por conseguinte, a arte também é literatura no momento que condensa a palavra por meio de uma imagem.

O texto de $1 Q 84$ permitiu aprofundar os conceitos de espaço e tempo, entendendo assim, sua importância na literatura. O espaço, principalmente, é o perder-se nos percursos, revelações, mais percursos, encontros, nascer e nascer em lugares que se decifram a cada curva da obra, a mesma e outra história, ruas desertas que recebem moradores antigos degustando um novo falar, mato nascendo nas telhas e beirais de uma narrativa já existente, redesenho auxiliado por um compasso cuidadoso, mapa marítimo lido por outros povos que se assustam do mesmo modo que os primeiros leitores de outrora, enfim, o cenário certo para entender a palavra compilada.

Sabe-se que a lógica da criação perpassa culturas e estilos. Haruki Murakami não fugiu disso, mas imprime nela certo mistério e os cenários corroboram para que o leitor atualize tais sensações. Analisando diversas vezes o método da escrita do escritor japonês, é possível ver traços do mundo real na ficção. No entanto, é tudo criação. É o mundo da palavra.

\section{REFERÊNCIAS}

BACHELARD, Gaston. A poética do espaço. São Paulo: Martins Fontes, 1993.

BARTHES, Roland. O prazer do texto. Tradução J. Guinsburg. São Paulo: Editora Perspectiva, 1987. BEMONG, N. et al. Bakhtin's theory of the literary chronotope. Academia Press, 2010. 
BLANCHOT, Maurice. O espaço literário. Tradução de Álvaro Cabral. Rio de Janeiro: Rocco, 1987.

DELEUZE, Gilles. Crítica e clínica. Tradução de Peter Pál Pelbart. São Paulo: Editora 34, 2011.

DIDI-HUBERMAN, Georges. A sobrevivência dos vaga-lumes. Tradução de Vera Casa Nova e Marcia Árbex. Belo Horizonte: Editora UFMG, 2011.

FOUCAULT, Michel. O que é um autor? In: Ditos e escritos: estética-literatura, música e cinema (vol. III). Rio de janeiro: Forense Universitária, 2001.

LINS, Osman. Lima Barreto e o espaço romanesco. São Paulo: Ática, 1976 (Ensaios, 20).

LINS, Osman. Avalovara. São Paulo: Companhia das Letras, 2005.

MURAKAMI, Haruki. 1Q84. Tradução de Lica Hashimoto. Rio de Janeiro: Objetiva, 2012 - tomo I.

MURAKAMI, Haruki. 1Q84. Tradução de Lica Hashimoto. Rio de Janeiro: Objetiva, 2013 - tomo II.

MURAKAMI, Haruki. 1Q84. Tradução de Lica Hashimoto. Rio de Janeiro: Objetiva, 2013 - tomo III.

NOHIRO, Kato. Murakami Haruki wa, muzukashii. Japan: Iwanami, 2015.

ROSENFELD, Anatol. Literatura e personagem. In: CANDIDO, Antonio et al. A personagem de ficção. São Paulo: Perspectiva, 2002.

RUBIN, Jay. Haruki Murakami and the Music of Words. London: The Harvill Press, 2002.

SEATS, Michael. Murakami Haruki: the simulacrum in contemporary Japanese culture. USA, Lexington Books, 2009.

VUKANOVIC, M. Grmusa, L. Space and Time in Language and Literature. Cambridge Scholars Pub., 2009. 


\section{ANEXOS}

Representação imagética dos personagens de $1 Q 84$

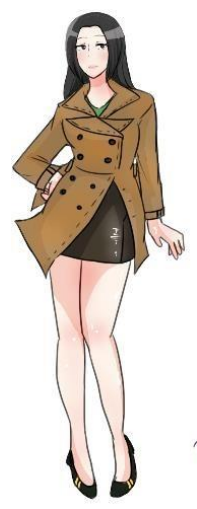

Figura 1 - Aomame

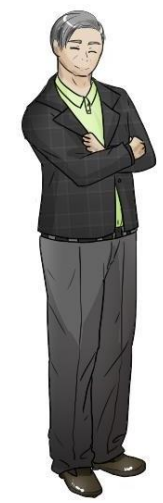

Figura 2 - Komatsu

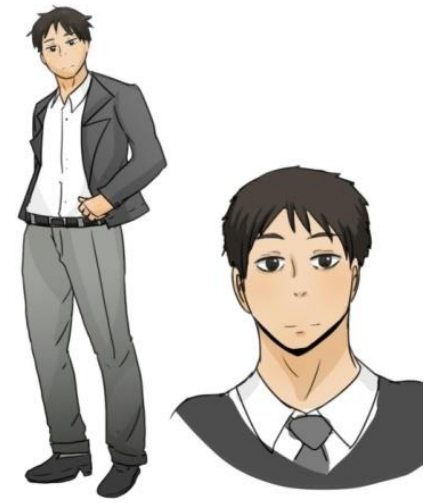

Figura 3 - Tengo
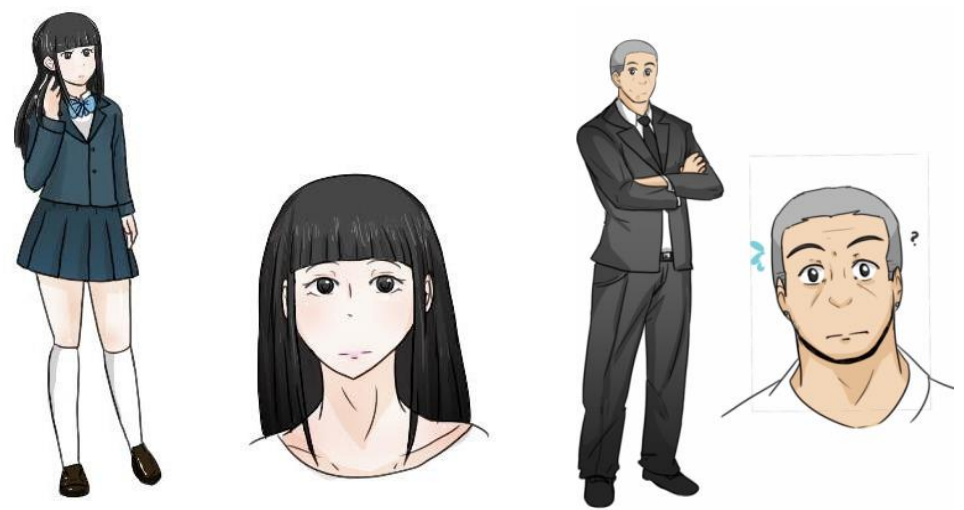

Figura 5 - Tamaru

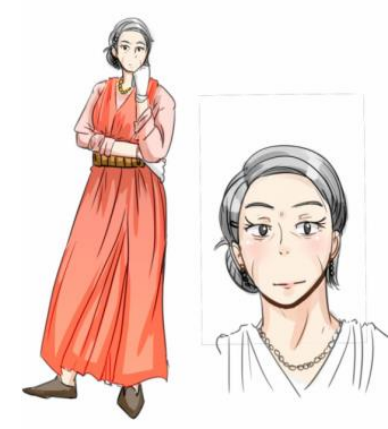

Figura 6 - A Proprietária 


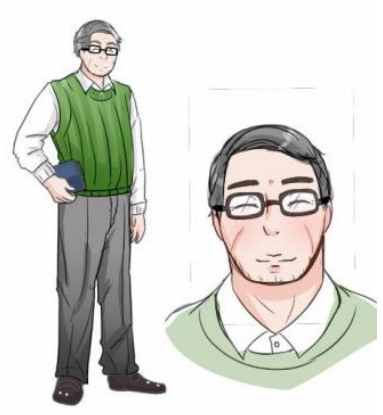

Figura 7 - Professor Ebisuno

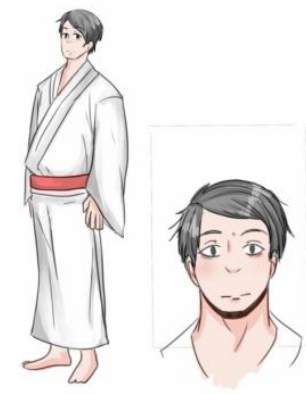

Figura 8 - Líder Fukada

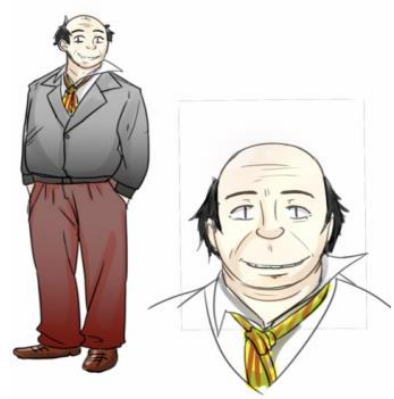

Figura 9 - Ushikawa

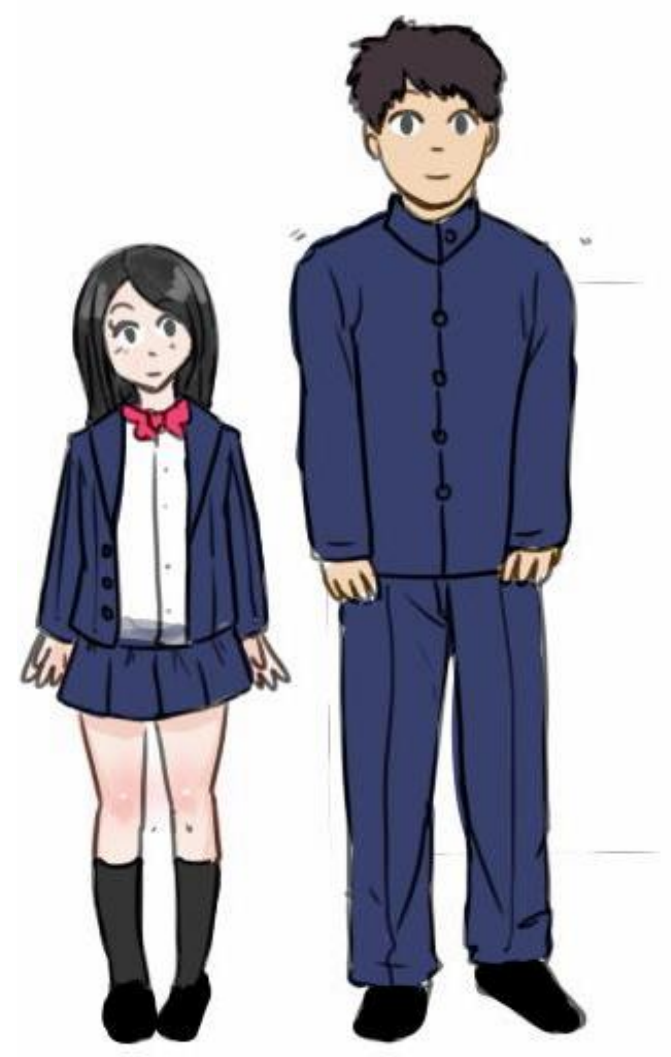

Figura 10 - Aomame e Tengo no colegial 


\section{Representação imagética dos espaços em 1Q84}

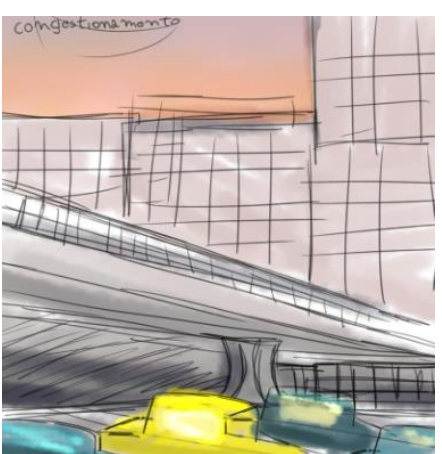

Figura 1- Via Expressa No 3

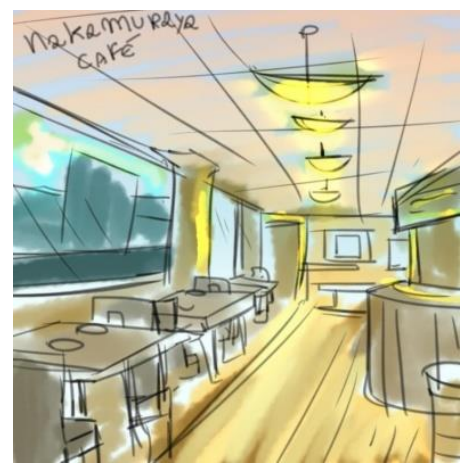

Figura 2- Nakamuraya Café

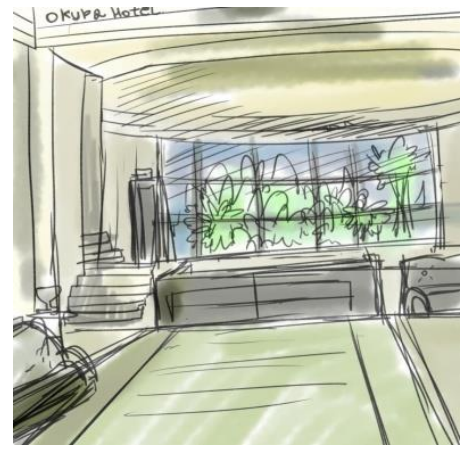

Figura 5- Hotel Okura, Toranomon, Tokyo

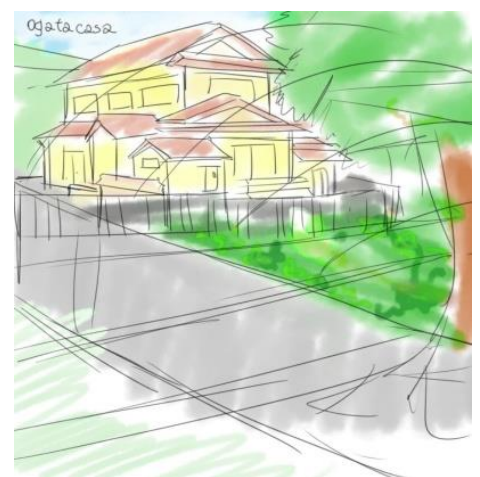

Figura 3- Azabu, Tokyo

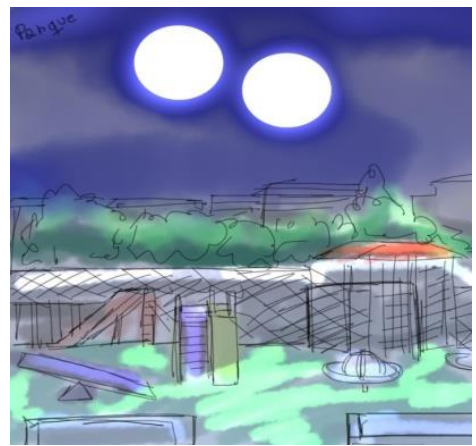

Figura 6- Kôenji

Fotografias dos lugares desenhados acima

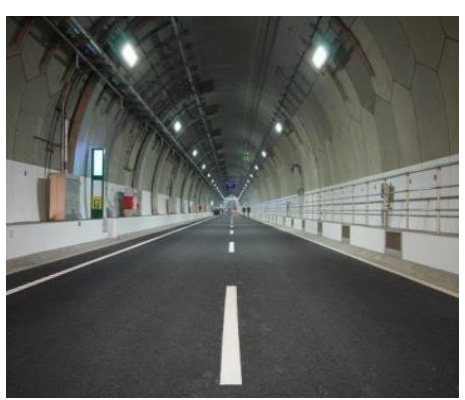

Imagem 7 - Via Expressa, em Yamato.

Fonte: http://wporep.blog.so-net.ne.jp/ Acesso em 21/2/2019.

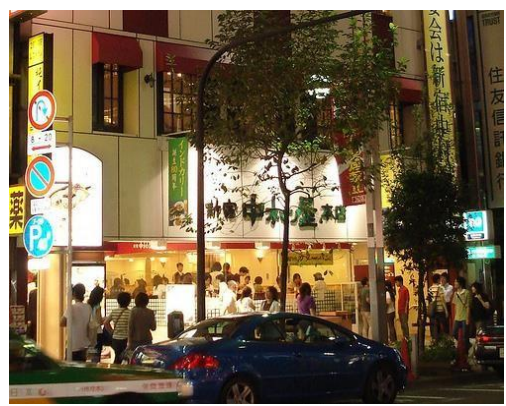

Imagem 8 - Nakamuraya Café Fonte:<http://www.camemberu.com/2007/0 9/nakamuraya-at-shinjuku.html>. Acesso em 21/2/2019.

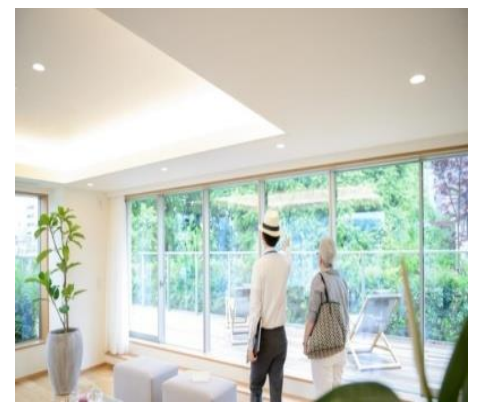

Imagem 9 - Casa com Jardim em Azabu

Fonte:http://www.azabugardens.com/bl og/home-away-home. Acesso em $21 / 2 / 2019$ 


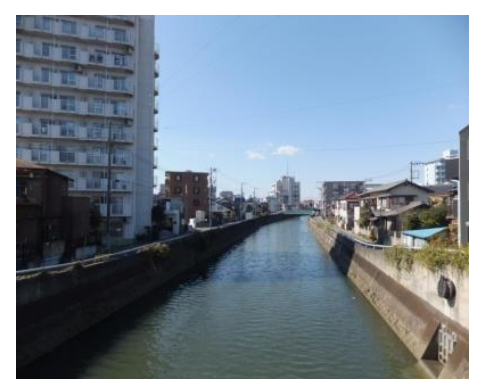

Imagem 10 - Passagem do Rio de Chiba.

Fonte:https://commons.wikimedia.org/wi ki/User:\%E6\%8E\%AC\%E8\%8C\%B6. Acesso em 21/2/2019.

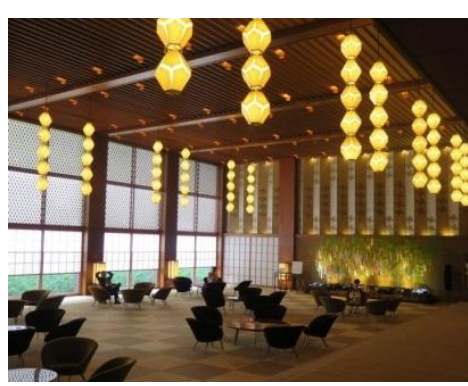

Imagem 11 - Hotel Okura Fonte:http://colorfulcities.com/a-fondadieu-hotel-okural. Acesso 21/2/2019.

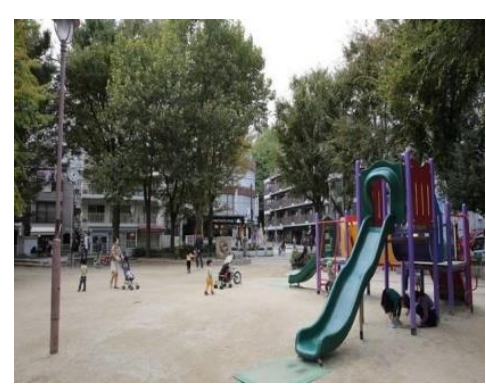

Imagem 12 - Parque de Kôenji Fonte:http://www.timeout.jp/tokyo/ja. Acesso em 21/2/2019. 